R. J. Cohen and W. T. Sullivan, III, eds.

\title{
Light Pollution in Quebec
}

\author{
Yvan Dutil \\ Observatoire du Mont Mégantic
}

\begin{abstract}
.
As in any developed country, light pollution is a serious problem in Quebec. However, a specific cultural and economical situation forces us to use new tactics when it is time to discuss this problem. As an example, using energy loss as an argument against light pollution is very inefficient since the electricity is cheap (US\$0.04/kWh) and clean (hydroelectricity). On the other hand, using the negative ecological impacts of light pollution appears to be the most effective way to create awareness in the population
\end{abstract}

\section{Introduction}

Interest in the fight against light pollution has grown in the last five years in Quebec. It began when professional astronomers realized the threat of light pollution that would be soon faced by the only research observatory in Quebec. Rapidly the amateur astronomers joined the battle. Now, the astronomical community at large is well organized and is starting to spread the word to the general public.

With a price of Can $\$ 0.06 / \mathrm{kWh}(\mathrm{Can} \$ 1=\mathrm{US} \$ 0.68$ at $08 / 99)$, the electricity in Quebec is cheap. This simple fact delayed the introduction of efficient lighting methods. Nevertheless, for some time, Hydro-Québec, the government-owned electricity producer has subsidized the change of streetlights to more energy efficient models. Unfortunately, this programme is now finished. Meanwhile, some cities have changed their street lighting system from the old "cobra" mercuryvapour type to a much more efficient "Helios" high-pressure sodium (HPS) full cut-off type, locally produce by Lumec-Schréder. However, most cities chose to limit the cost of the transformation and simply replaced the mercury-vapour lamp with a HPS lamp. Nevertheless, this street lighting looks good when compared to most systems used for domestic or industrial applications, such as the standard unshielded 175-W mercury-vapour "security light" used by farmers. Conservative calculations based on DMSP data (Isobe 1999) estimate the cost of energy loss for the whole of Quebec to be Can $\$ 45$ millions per year (760 $\mathrm{GWh} / \mathrm{yr})$.

However, in a country where the sky is clouded two nights out of three, where there is 14 hours of darkness in winter and where the electricity is one of the cheapest in the world, we are fighting an uphill battle. Fortunately, we are bringing into the battle the ecological groups that are starting to consider light as another menace to the environment. 


\section{Educational Activities}

In 1995 I established a web page (http://astro.phy.ulaval.ca/astro/pol Jum.html) about light pollution in Quebec. At that time, it was one of the first web pages written in French on this subject. Today, this site receives a few thousand visitors per year and is referenced throughout the world. In the last few years, many astronomical events (comets Hyakutake and Hale-Bopp, Perseid and Leonid meteor showers) have been used to awake the public to the problem. Ironically, the Znamya satellite reflector project was one of the most useful events to raise this issue, thanks to the tremendous media coverage it received.

Also in 1995, the Fédération des Astronomes Amateurs du Quebec (FAAQ) gave birth to their "Comité Ciel-Noir". In collaboration with the lighting industry and professional astronomers, this committee produced a document about the protection of the night sky. It is an intervention guide for those who want to establish a lighting regulation. This document is now broadly available in its printed or electronic version (http://www.quebectel.com/faaq/cielnoir.htm). In addition, this committee also produced a nice report that was published in Québec-Science, the largest popular science magazine in Quebec.

Two other astronomical institutions are also strongly involved in public education. The Astrolab du Mont Mégantic, the visitor centre of the Mont Mégantic Observatory, is probably the most committed to this task. In addition to its own education programme explaining the importance of the dark sky for astronomers, the Astrolab's future is preserved by protecting its own dark sky around Mont Mégantic through informing local authorities about actions to be taken. The Planétarium de Montréal has its own way to explain the problem to its public. During the presentation, they simulate the effect of light pollution on the visibility of the stars. Therefore spectators can directly compare between a light-polluted environment and a dark one. Employees of the planetarium have also written to local newspapers about the ecological problems caused by artificial lighting.

\section{The Mont Mégantic Observatory}

Jointly operated by Université de Montréal and Université Laval, the Mont Mégantic Observatory is the only major telescope $(1.6 \mathrm{~m})$ in eastern Canada. It is built in one of the last relatively dark regions in southern Quebec. Site selection analysis made in the seventies estimated the light pollution at about $25 \%$ of the natural background level. Now it is certainly higher, some observers estimating it as much as $50 \%$ of the natural background. In order to establish the main sources of pollution, we have estimated the relative contributions of nearby towns by using the Walker law (Walker 1977). This coarse study allows us to pinpoint the largest polluters at the observatory site. Small towns near the observatory are the strongest contributors; about half of the overall pollution comes from less than $25 \mathrm{~km}$. An additional $30 \%$ comes from the city of Sherbrooke (population 120000 ) situated at $55 \mathrm{~km}$. Future analysis will be based on satellite data and a model of the atmosphere in order to establish more accurately the contributions of different sources (see Cinzazo 2001 in these proceedings). 
Since about half of the light comes from the nearby but relatively unpopulated region, significant improvement could be expected at little expense, In addition, Lumec-Schréder is designing a cheap version of its "Helios" system, a full cutoff-light fixture, in order to facilitate its utilisation for domestic use. If farmers adopt this system instead of their monstrous mercury-vapour lamps, this alone may be enough to restore most of the original darkness of this rural sky.

To finish on a positive note, I shall note the interest of local communities around Mont Mégantic Observatory for protection of the night sky. At this moment, discussions between the Observatory, the Astrolab, the Fédération des Astronomes Amateurs du Québec, local and county authorities and the lighting industry (Lumec-Schréder) is taking place about future installation of appropriate lighting fixtures in the surrounding region.

\section{Political Action}

The first major political action against abusive lighting was carried out in July 1997. At that time, a new casino was inaugurated in the city of Hull, near Ottawa. The administration of the casino had the bright idea of using high intensity projectors to attract gamblers like moths! Overall, it took one month of protests from amateur astronomers and ordinary citizens upset by the horrendous beam of light, a petition of a few hundred names, motions by nearby city councils and many articles and editorials in newspapers to force them to shut down their system indefinitely.

Unfortunately, things are not always so easy. The next fight was organized against the proposal of the Commission de la Capitale Nationale, which wants to transform Quebec City into a "Ville Lumière". To do so, they plan to illuminate 63 sites around Quebec City: buildings, bridges, falls, cliffs, etc. An international protest campaign (support by IDA members) and a petition did not induce any positive reaction from the authorities. In addition, a group of ornithologists from Toronto (FLAP) alerted the Commission de la Capitale Nationale to the dangers to birds of lighting buildings. To the inquiry of a journalist, their only comment was: "the lamps used are too faint to create any problem". However, they naively admitted that the electricity bill for one of their sites was "only" Can $\$ 15$ per day. If we extrapolate from this statement, the overall "Plan Lumière" will increase the upgoing light for the region of Quebec City by at least $10 \%$; locally, the effect will be even larger. We have not given up yet, but in the short term it appears they will continue with their project with the blessing of the local and provincial authorities.

\section{Enlisting More Troops}

The astronomical community is very small in Quebec. Overall, there are about 15 professional astronomers and a few hundred amateur astronomers. Obviously, it will be extremely difficult to change the mind of the governments without some external support. Attempts have been made to get the attention of ecological groups. So far results have been limited but significant. 
Actions such as those above should only be attempted if you have access to a complete and detailed description of direct effects of light pollution in ecological terms. We had access to such a document, thanks to the French astronomical community. The document "Impacts écologiques de l'éclairage nocturne" was written by François Lamiot following the "Premier Congrès européen sur la protection du ciel nocturne" in May 1998. This is a compilation of effects of artificial lighting observed on birds, insects and even snails! We have distributed it to a large number of ecological groups in Quebec. It can also be downloaded (http://ecoroute.uqcn.qc.ca/gen/bull/index.html) from the web site ÈcoRoute de l'Information supported by l'Union Québécoise pour la Conservation de la Nature. Following this intervention, some "green" associations have demonstrated their interest.

Finally, I want to emphasize the fact that media tend to be more receptive to the environmental impact of artificial lighting than to the astronomical aspect of the problem. Therefore, in order to use this particular sensitivity, volunteers should have access to a good database of direct effects of artificial light on wildlife and on human life. Such a database would be an invaluable weapon in the battle against light pollution.

\section{Conclusion}

The particular cultural and economical situation produces an especially high level of light pollution in Quebec. Fortunately, in the last few years we have seen an increase of awareness in the astronomical community. Now, this awareness is growing beyond the ranks of astronomers and is reaching the ecological community plus a segment of the general population. We expect to harvest soon the fruits of this education process.

\section{References}

Cinzazo, P. 2001, in these proceedings

Isobe, S. 1999, private communication

Walker, M. F. 1977, PASP, 89, 405-409 